\title{
Joëlle Gardes Tamine et Marie-Claude Hubert, Dictionnaire de critique littéraire
}

\section{Fatima Pilone}

\section{Q OpenEdition}

1 Journals

\section{Edizione digitale}

URL: http://journals.openedition.org/studifrancesi/34026

DOI: 10.4000/studifrancesi.34026

ISSN: 2421-5856

\section{Editore}

Rosenberg \& Sellier

\section{Edizione cartacea}

Data di pubblicazione: 1 décembre 2005

Paginazione: 702-703

ISSN: 0039-2944

\section{Notizia bibliografica digitale}

Fatima Pilone, «Joëlle Gardes Tamine et Marie-Claude Hubert, Dictionnaire de critique littéraire», Studi Francesi [Online], 147 (XLX | III) | 2005, online dal 30 novembre 2015, consultato il 18 avril 2021. URL: http://journals.openedition.org/studifrancesi/34026; DOI: https://doi.org/10.4000/studifrancesi. 34026

Questo documento è stato generato automaticamente il 18 avril 2021.

\section{(c) $(1) \ominus$}

Studi Francesi è distribuita con Licenza Creative Commons Attribuzione - Non commerciale - Non opere derivate 4.0 Internazionale. 


\title{
Joëlle Gardes Tamine et Marie- Claude Hubert, Dictionnaire de critique littéraire
}

\author{
Fatima Pilone
}

\section{NOTIZIA}

JoËLLE GARDES TAMINE et MARIE-CLAUDE HUBERT, Dictionnaire de critique littéraire, Armand Colin, Collection Dictionnaire, Paris, 2004, pp 240.

1 Questo dizionario, a cura di due docenti dell'Université de Provence, intende definire i termini che possono essere incontrati in una qualsiasi opera di critica letteraria o utilizzati per redigere una qualsiasi analisi del testo.

2 Un vero e proprio dizionario, dunque, che inizia con la parola Abstraction e si conclude con Zutistes.

3 Joëlle GARDES TAMINE e Marie-Claude HUBERT analizzano più di settecento concetti, in un sistema di renvois che permette al lettore di orientarsi all'interno del testo e, di conseguenza, nelle varie discipline trattate.

4 Prima di tutto, viene fornita una definizione della parola, con un preciso riferimento all'etimologia, per poi riflettere anche su tutta una serie di significati per estensione. In seguito, ogni singola definizione è avvalorata da esempi assortiti e da citazioni, prese da autori che vanno dall'antica Grecia sino ai giorni nostri. Infine, un elenco di opere che possiamo leggere sull'argomento, per approfondire le nostre riflessioni. A completare il dizionario, oltre a più di quattrocento rubriche, un indice dei termini definiti all'inizio di ogni singola rubrica ed una bibliografia generale.

5 L'opera è composta da un vocabolario preso in prestito alle discipline più diverse, dalla linguistica alla retorica, dalla critica alla storia letteraria, passando per le diverse correnti della critica stessa all'ambito letterario in senso stretto, con i suoi generi, le 
analisi tematiche e le scuole di pensiero, per giungere alle nozioni fondamentali della storia letteraria e della critica testuale, con alcuni elementi di narrativa, drammaturgia e poetica.

6 Il Dictionnaire de critique littéraire si rivolge a tutti coloro che devono quotidianamente confrontarsi con la critica letteraria, per la propria professione o i propri studi ma anche a livello delle proprie letture in qualità di non specialisti. Risulta quindi essere un valido strumento nell'approccio critica ad un testo letterario. 